\title{
A BANALIZAÇÃO DA POBREZA NO BRASIL A PARTIR DAS CONCEPÇÕES DE AMARTYA SEN
}

THE TRIVIALIZATION OF POVERTY IN BRAZIL FROM THE CONCEPTIONS OF AMARTYA SEM

\section{Leilane Serratine Grubba ${ }^{1}$ \\ Angélica da Silva Corrêa}

\section{Resumo}

O artigo tem como tema central a defesa da ideia da banalização da pobreza no Brasil a partir das concepções desenvolvidas por Amartya Sen, com o fito de indagar em que medida o "ser pobre" influencia na exclusão social e na banalização do indivíduo. O objetivo geral é examinar de que maneiras a pobreza poderá privar o ser humano de exercer suas capacidades em diversos espaços e circunstâncias em que ele está incluído. A fim de situar o leitor, o trabalho possui dois capítulos, o primeiro focado no conceito de pobreza e seu desenvolvimento, com um olhar sobre o impacto da pobreza no Brasil, assim como, na banalização e exclusão social do pobre; e o segundo, com o enfoque na questão da pobreza como supressão das capacidades a

\footnotetext{
${ }^{1}$ Doutora e Mestre em Direito pela Universidade Federal de Santa Catarina. Professora do Programa de Pós-Graduação Stricto Sensu em Direito do Complexo de Ensino Superior Meridional (IMED). Professora da Escola de Direito do Complexo de Ensino Superior Meridional (IMED). Pesquisadora da Fundação Meridional. Líder do Centro de Direito, Democracia, Desenvolvimento e Sustentabilidade, da Faculdade Meridional. Pesquisadora do Núcleo de Estudos Conhecer Direito (NECODI). Pesquisadora Coordenadora do Projeto de Pesquisa FUNDDIH - Fundamentos e Dimensões dos Direitos Humanos (IMED/CNPq), além do Projeto de Pesquisa MAR - Migração, Apatridia e Refúgio (IMED/CNPq). Pesquisadora Coordenadora do Projeto de Pesquisa e Extensão CineLaw (Cinema, Direitos Humanos e Sociedade: vias para o empoderamento) (CNPq/IMED/Instituto Interamericano de Derechos Humanos IIDH/ Youth for Human Rights YHRB). Membro do Corpo Diplomático e Consultora de Projetos do Programa das Nações Unidas Youth for Human Rights (YHRB). Publicou os livros O Essencialismo nos Direitos Humanos, Conhecer Direito I e Conhecer Direito II. Atualmente tem como tema central de pesquisa os Processos de produção do conhecimento na área do Direito e os Direitos Humanos, com ênfase em Desenvolvimento Humano, Migrações e Cinema. E-mail: Isgrubba@hotmail.com

2 Mestranda em Direito da Faculdade Meridional de Passo Fundo (IMED), Linha de Pesquisa - ॥ Mecanismos de Efetivação da Democracia e da Sustentabilidade - Área de concentração - Direito, Democracia e Sustentabilidade. Bolsista PROSUP/CAPES.Possui graduação em Direito pela Faculdade Metodista de Santa Maria (FAMES) - 2016. Ex- estagiária do gabinete do Juizado da Infância e Juventude de Santa Maria. Advogada. Técnica em Segurança do trabalho pelo Sistema Educacional Galileu de Santa Maria - SEG. Tem experiência na área financeira, segurança do trabalho, administrativa, com ênfase em recursos humanos e departamento de pessoal. Pesquisa na área de Direito Humanos, Direito Penal, Processo Penal e Criminologia. Linha de pesquisa: Sistema Prisional; Direitos Humanos, Políticas Públicas para a população carcerária. E-mail: angelicacorrea1418@gmail.com
} 
partir das concepções de Amartya Sen. Para tanto, o método de abordagem que servirá de referência para análise das ideias, informações e resultados desta pesquisa é o método dedutivo, juntamente como os métodos de procedimento monográfico e histórico, a fim de ofertar um estudo pontual e específico acerca de uma questão crítica na seara social. Logo, a técnica de pesquisa consistirá na bibliográfica. A hipótese apresentada sugere que, embora a trajetória da pobreza apresente características peculiares, conforme as perspectivas de Amartya Sen, é notório que em todos eles há a predominância de situações de empobrecimento, precariedade e de exclusão social de vastos contingentes populacionais. Esse fato, por sua vez, também parece apontar a construção ideológica de uma divisão social, econômica, cultural e política entre ricos e pobres, abastados e destituídos, sob a aparência de normalidade (neutralidade), implicando a ideia de banalização.

Palavras-chave: Direito, Direitos Humanos; Amartya Sen; Capacidades; Pobreza.

\section{Abstract}

The main theme of the article is the idea of poverty's banalization in Brazil, based on the conceptions developed by Amartya Sen. We seek to investigate the extent to which "being poor" influences the social exclusion. The overall objective is to examine in what ways poverty can deprive a human being of exercising his abilities in the various spaces and circumstances in which he is included. In order to situate the reader, the work has two chapters, the first focuses on the concept of poverty and its development, with a look at the impact of poverty in Brazil, as well as on the banalization and social exclusion of the poor; and the second, with the focus on the issue of poverty as a suppression of capacities, we analyze the conceptions of Amartya Sen. For this, the deductive method will serve as a reference, information and results for this research. Also, complementarily, the use of monographic and historical procedures. Therefore, the research technique will consist of the bibliographical one. The hypothesis presented suggests that, although the trajectory of poverty presents peculiar characteristics, according to the perspectives of Amartya Sen, it is evident that in all of them there is a predominance of situations of impoverishment, precariousness and social exclusion of vast population contingents. This, in turn, also seems to point to the ideological construction of a social, economic, cultural and political division between rich and poor, under the guise of normality (neutrality), implying the idea of trivialization. 
Keywords: Law; Human Rights; Amartya Sen; Capabilities; Poverty.

\section{INTRODUÇÃO}

A problemática da pobreza e da sua consequente banalização nas sociedades contemporâneas vem sendo abordada cientificamente há bastante tempo e é o principal objetivo deste artigo, que trata da pobreza no Brasil como problemática que tem alcançado patamares de exclusão social e banalização do indivíduo como ser humano digno. É notório que essa questão sempre esteve presente, assim como também se verificam historicamente algumas formas ou ações de enfrentamento. Todavia, o que se tem sido registrado no decorrer das últimas décadas é que o Brasil, em virtude de grandes crises econômicas, vem aumentando o número de pessoas que se encontram em situação de pobreza, agravando a privação de capacidades de determinados indivíduos.

É sobre essa temática que trata este trabalho que resulta de levantamentos bibliográficos desenvolvidos acerca do tema no âmbito da Pesquisa sobre "Avaliação do Fundo de Combate e Erradicação da Pobreza no Brasil" do Banco Mundial (2017) e que se efetiva no contexto da pesquisa em questão.

O objetivo deste artigo é problematizar a ideia da banalização da pobreza no Brasil a partir das concepções teóricas desenvolvidas por Amartya Sen, complementando o estudo pela avaliação do Banco Mundial sobre os "novos pobres" durante a crise econômica brasileira.

Metodologicamente, na primeira parte do artigo serão descritas as abordagens do fenômeno social e econômico da pobreza e o seu desenvolvimento ao longo do último século. Assim, inicialmente, serão pontuadas as categorias nas quais se enquadram os conceitos de pobreza: pobreza como juízo de valor, pobreza relativa, pobreza absoluta e pobreza relativa/absoluta. Posteriormente, será analisado o impacto da pobreza no Brasil, tratando sobre a banalização e exclusão social do pobre no contexto atual. Na segunda parte se discutirá a visão de Amartya Sen sobre a pobreza e sua relação com o conceito de privação de capacidades e alternativas de funcionamentos de possível realização. Na conclusão, será feito um apanhado geral do artigo, enfatizando seu objetivo primeiro: ser uma singela contribuição para a discussão em relação a banalização da pobreza no Brasil. Por fim, serão apresentadas algumas reflexões a título de conclusão acerca dos estudos realizados com base na bibliografia consultada. 


\section{O CONCEITO DE POBREZA E SEU DESENVOLVIMENTO HISTÓRICO CONTEMPORÂNEO}

A seção se dedica a um sucinto estudo em relação ao conceito de pobreza e de seu desenvolvimento no vigente século. A definição dessas concepções torna-se essencial na pesquisa, pois permite uma visão analítica do objeto de estudo.

O significado etiológico da palavra pobre veio do latim "pauper", radicado em "paucus", pouco. No conceito original, pobre não é quem tem pouco, mas quem produz pouco. O étimo está ligado a "parere", produzir, aplicado tanto às aves poedeiras quanto às mulheres que dão à luz, pois ambas produzem (HR IDIOMAS).

Logo, o conceito de pobreza pode ser entendido como o estado de carência de um sujeito cujo bem-estar é inferior ao que a sociedade é moralmente obrigada a garantir. Por isso, a consideração concreta do que se estabelece como "ser pobre" é algo extremamente complexo e pode ser feita levando em conta algum "juízo de valor", em termos relativos ou absolutos (ONU, 2017).

Por isso, a pobreza, quando categorizada como "juízo de valor", trata de uma visão subjetiva e abstrata do indivíduo acerca do que deveria ser um grau suficiente de satisfação de necessidades, ou do que deveria ser um nível de privação normalmente suportável. Desse modo, tal enfoque não esconde sua fragilidade, embora seja bastante óbvio que mesmo uma conceituação objetiva da pobreza não se furta à presença de algum juízo de valor (CRESPO; GUROVITZ, 2002).

Por outro lado, a definição de pobreza pode ser estudada ora do ponto de vista econômico, ora incorporando aspectos não-econômicos, sendo contextualizada de modo dependente ou não da estrutura sócio-política da sociedade (CRESPO; GUROVITZ, 2002).

Também se faz necessário estabelecer uma medida do bem-estar individual e da definição do mínimo de bem-estar moralmente aceitável, quantificado na mesma unidade de medida. Aqui se apresenta a problemática levantada na introdução do artigo, pois não há consenso sobre o que é o bem-estar, sobre como medi-lo, e muito menos sobre qual é o mínimo de bem-estar moralmente aceitável (OSORIO; SOARES; SOUZA; 2011).

Conforme afirma Soares (2009), ainda há diferentes propostas de abordagem para se definir a pobreza, isto é, se a pobreza deve ter uma relação estreita com necessidades nutricionais ou se as necessidades básicas dependem de parâmetros culturais e sociais. Ainda, 
se a pobreza se reduz ou não à insuficiência de renda, se a condição de pobreza é absoluta ${ }^{3}$ ou deve variar com a evolução de renda da sociedade. Por isso, explicações diferentes a cada uma destas perguntas levam a abordagens distintas para o cálculo da linha de pobreza.

Portanto, a opção por padrões de pobreza não se trata de um perfeccionismo estatístico. As definições sobre quais os conceitos que se deve usar são extremamente importantes, pois diferentes parâmetros podem levar a conclusões completamente distintas. $\mathrm{Na}$ verdade, essa escolha reflete valores morais e, no limite, pode determinar políticas de combate à pobreza totalmente diferentes (MEDEIROS, 2012).

Nesse contexto, a pobreza pode ser entendida em vários sentidos, principalmente:

a) carência cogonal: tipicamente envolvendo as necessidades da vida cotidiana como alimentação, vestuário, alojamento e cuidados de saúde. Pobreza, nesse sentido, pode ser entendida como a carência de bens e serviços essenciais (PNUD, 2013);

b) falta de recursos econômicos: a carência de rendimento ou riqueza, não necessariamente apenas em termos monetários. As medições do nível econômico são baseadas em níveis de suficiência de recursos ou em "rendimento relativo". A União Europeia identifica a pobreza em termos de "distância econômica" relativamente a $60 \%$ do rendimento mediano da sociedade (PNUD, 2013);

c) carência social: a exclusão social, a dependência e a incapacidade de participar na sociedade. Isto inclui a educação e a informação. As relações sociais são elementos chave para compreender a pobreza pelas organizações internacionais, as quais consideram o problema da pobreza além da economia (PNUD, 2013).

Segundo as considerações estabelecidas pelo Banco Mundial ${ }^{4}$ (2014), apesar de a pobreza mais grave se encontrar nos países subdesenvolvidos, esta existe em todas as regiões. Nas nações desenvolvidas, manifesta-se através da existência de pessoas sem-teto e de lugares denominados de favelas, onde concentram-se a maior parte das pessoas pobres do país.

O Banco Mundial, na década de oitenta (1990), definiu a pobreza extrema como viver diariamente com menos de um dólar estadunidense (em paridade do poder de compra) e pobreza moderada como viver com entre um e dois dólares estadunidenses diários. Estima-se que um bilhão e cem milhões de pessoas a nível mundial tenham níveis diário de consumo

\footnotetext{
${ }^{3}$ A pobreza absoluta refere-se a um nível que é consistente ao longo do tempo e entre países. Um exemplo de um indicador de pobreza absoluta é a percentagem de pessoas com uma ingestão diária de calorias inferior ao mínimo necessário (aproximadamente $2000 / 2500$ quilocalorias) (PNUD, 2013).

4 O Banco Mundial é uma instituição financeira internacional que efetua empréstimosa países em desenvolvimento. É o maior e mais conhecido banco de desenvolvimento no mundo, além de possuir o status de observador no Grupo de Desenvolvimento das Nações $U$ Unidas ${ }^{[1]} \mathrm{e}$ em outros fóruns internacionais, como o G-20 financeiro. A sede do banco está situada em Washington, D.C., Estados Unidos da América. O Banco Mundial é parte do Grupo do Banco Mundial (WORK BANK).
} 
inferiores a um dólar dos Estados Unidos, e que dois bilhões e setecentos milhões tenham um nível inferior a dois dólares dos Estados Unidos 5 .

No entanto, o padrão referido acima de um dólar diário por pessoa, medido em preços internacionais no ano de 1985 e ajustado à moeda local usando Poder de Paridade de Compra (PPC) foi superado, porque este valor era típico nas linhas de pobreza dos países de baixa renda na época. À medida que as diferenças no custo de vida em todo o mundo evoluíram, a linha internacional de pobreza tem de ser periodicamente atualizada usando novos dados de preços PPC para refletir essas mudanças. A última mudança ocorreu em outubro de 2015 , quando o Banco Mundial adotou um dólar e noventa centavos como linha de pobreza internacional usando o PPC de 2011. Antes disso, a atualização de 2008 definiu a linha de pobreza internacional em um dólar e vinte e cinco centavos usando o PPC de 2005 (ONU, 2017).

Um dos indicadores mais utilizados para o monitoramento da pobreza é o número absoluto de pobres extremos. A inclusão da renda não monetária ou a opção pelo consumo como indicador de bem-estar, embora conceitualmente sólidas, são costumeiramente descartadas, em função das dificuldades de medição. Linhas definidas a partir de necessidades calóricas também costumam ser descartadas por não serem adequadas nem para a definição nem para o monitoramento - uma vez que produzem linhas que variam segundo características das famílias (ONU, 2017).

A proporção de pobres também é um indicador bastante usado como medida de incidência da pobreza, embora ela seja insensível à intensidade da pobreza entre os pobres. Isso porque a linha de pobreza estabelece um critério binário que divide os indivíduos em pobres e não-pobres, de modo a tratar pessoas que estão a apenas um centavo abaixo da linha de pobreza e pobres na miséria absoluta indiferentemente. De acordo o Documento Temático do Objetivo de Desenvolvimento Sustentável (ODS) de Erradicação da Pobreza da ONU:

Ainda assim, para calcular esta linha, é necessária uma definição sobre o que é uma pessoa pobre. Além da identificação da pobreza, a sua mensuração demanda a escolha por uma unidade de análise. Essa unidade pode ser, por exemplo, o indivíduo, o domicílio ou a família (ONU, 2017, p.3).

Em contrapartida, a concepção da pobreza como conceito relativo é uma abordagem de cunho macroeconômico, assim como o conceito de pobreza absoluta. A pobreza relativa tem relação direta com a desigualdade na distribuição de renda. É explicitada segundo o padrão de

\footnotetext{
${ }^{5}$ Também é importante a consideração da diferença de gênero na identificação da pobreza a nível mundial. Em todas as sociedades, das mais altas em desenvolvimento humano às mais baixas, as mulheres apresentam menores rendimentos per capita que homens (ONU, 2016, p. 211).
} 
vida vigente na sociedade que define como pobres as pessoas situadas na camada inferior da distribuição de renda, quando comparadas àquelas melhor posicionadas. Assim, a sua caracterização é descrita como aquela situação em que o indivíduo, quando comparado a outros, tem menos de algum atributo desejado, seja renda, sejam condições favoráveis de emprego ou poder. "Uma linha de pobreza relativa pode ser definida, por exemplo, calculando a renda per capita de parte da população" (CRESPO; GUROVITZ, 2002, p.3).

Contudo, essa afirmação, sob outra perspectiva, torna-se incompleta ao não deixar margem para uma noção de destituição absoluta, requisito fundamental para a conceituação de pobreza. De certa forma, isso acaba gerando ambiguidade no uso indiferente dos termos pobreza e desigualdade que, na verdade, não são sinônimos (CRESPO; GUROVITZ, 2002, p.3-4).

Em síntese, o sentido absoluto na análise conceitual da pobreza se verifica quando da fixação de padrões para o nível mínimo ou suficiente de necessidades, conhecido como linha ou limite da pobreza, o que determina a percentagem da população que se encontra abaixo desse nível. Ou seja, o padrão de vida mínimo, apresentado sob diferentes aspectos, seja nutricional, de moradia ou de vestuário, é normalmente avaliado segundo preços relevantes, calculando a renda necessária para custeá-los (ONU, 2017).

Ainda, para a determinação dos limites de pobreza se faz necessário diferentes enfoques, considerando-se o biológico, o das necessidades básicas ou o dos salários mínimos. Cada um dos enfoques identificados apresenta particularidades e natureza própria. Como exemplo, o enfoque das utilidades ou necessidades básicas, que engloba a alimentação, a moradia, o vestuário e os serviços essenciais, como o acesso à água potável, ao saneamento, ao transporte público, aos serviços médicos e à escolarização, etc. (ONU, 2017).

Com base nas diferentes abordagens sobre o conceito de pobreza descritos acima, três distinções merecem destaque e foram desenvolvidas no decorrer do século XX, sendo elas: (a) a sobrevivência; (b) as necessidades básicas; e, (c) a privação relativa (CRESPO; GUROVITZ, 2002, p.3).

Neste entendimento, o enfoque de sobrevivência, o mais limitado dos mencionados enfoques, marcou durante os séculos XIX e XX, aproximadamente até a década de 50. Sua origem foi fruto de estudos realizados por nutricionistas inglesas que apontaram que a renda dos mais pobres não era suficiente para a manutenção do rendimento físico do indivíduo. A Inglaterra adotou essa posição que veio a exercer uma grande influência em toda a Europa, sendo usada mais tarde pelo Banco Internacional para a Reconstrução e o Desenvolvimento (BIRD) (CRESPO; GUROVITZ, 2002, p.4). 
Através da utilização de medidas estatísticas, formulou-se o primeiro modelo de proteção social para o Estado de bem-estar, fundamentando políticas nacionais de assistência e alguns programas. Seus verdadeiros objetivos seriam limitar as demandas por reformas sociais e, ao mesmo tempo, preservar a ênfase no individualismo compatível com o ideário liberal. A maior crítica que esse enfoque sofreu foi que, com ele, justificavam-se baixos índices de assistência: bastava manter os indivíduos no nível de sobrevivência (CRESPO; GUROVITZ, 2002, p.4).

A partir de 1970, a ideia de pobreza apresentou sentindo voltado às necessidades básicas, demandando novas exigências, como serviços de água potável, saneamento básico, saúde, educação e cultura. Manteve-se o foco nas necessidades básicas, apontando certas exigências de consumo básico de uma família. Essa concepção passou a ser adotada pelos Órgãos Internacionais, sobretudo por aqueles que integram a Organização das Nações Unidas (ONU), representando uma ampliação da concepção de sobrevivência física simples (CRESPO; GUROVITZ, 2002, p.5).

A contar da década de oitenta, a pobreza passou a ser compreendida como uma carência relativa, dando ao conceito um sentido mais amplo e rigoroso, buscando uma formulação científica e comparações entre estudos internacionais, enfatizando o aspecto social. Dessa forma, "sair da linha de pobreza significava obter: um regime alimentar adequado, um certo nível de conforto, o desenvolvimento de papéis e de comportamentos socialmente adequados" (CRESPO; GUROVITZ, 2002, p.5).

Em contrapartida a este conceito, desenvolveu-se a questão que com o bom funcionamento dos mercados, as economias se tornariam prósperas, e a riqueza gerada acabaria por beneficiar os pobres. Essa asserção foi estimada pelas instituições multilaterais de crédito sediadas na capital norte-americana, e ficou sendo conhecida como "Consenso de Washington" (CRESPO; GUROVITZ, 2002, p.5).

No decorrer do tempo, a perspectiva sobre a pobreza relativa evoluiu, tendo como um de seus principais pesquisadores o indiano Amartya Kumar Sen, professor de Economia e Filosofia nas Universidades de Harvard e Thomas W. Lamont, ganhador do prêmio Nobel de Economia no ano de 1998. Sua concepção sobre o referido assunto estabelece elementos mais amplos, considerando o fato de que as pessoas podem sofrer privações em diversas dimensões da vida.

Logo, "ser pobre" não engloba somente a escassez material. Outras dimensões, que aqui serão apontadas, também determinarão o posicionamento dos cidadãos em outros níveis (OICH). Assim, no capítulo três será abordado de forma mais completa a problemática da pobreza como supressão das capacidades, a partir das concepções de Amartya Sen. 
Realizados, em síntese, os apontamentos sobre o conceito de pobreza e seu desenvolvimento, passamos a abordar o impacto da pobreza no Brasil, com enfoque na banalização e exclusão social da pobreza.

\section{O impacto da pobreza no Brasil: a banalização e exclusão social do pobre}

Para melhor entender o impacto da pobreza no Brasil, assim como a banalização e exclusão social do pobre, são necessárias algumas considerações preliminares acerca do conceito de banalização e exclusão social.

Hannah Arendt, filósofa política alemã de origem judaica, foi uma das mulheres mais influentes do século XX. O regime nazista retirou-lhe a nacionalidade em 1937, o que a tornou apátrida até conseguir a nacionalidade estadunidense em 1951. No ano de 1963, a filósofa lançou uma obra intitulada "Eichmann em Jerusalém", com o subtítulo "Relatório sobre a Banalidade do Mal", que reúne cinco artigos que ela escreveu sobre o julgamento de Eichmann - membro do partido nazista alemão - que cobriu para a revista The New Yorker. No mencionado livro, a autora traz, pela primeira, vez considerações filosófico-políticas acerca do bem e do mal. Apesar dos atos atentatórios à dignidade humana realiza dos pelo regime nazista e, consequentemente, por Eichmann, ela não o demonizou, mas o descreveu como alguém ao mesmo tempo monstruoso e normal, isto é, um típico burocrata que se limitara a cumprir ordens, com zelo, por amor ao dever (CENTRO DE ESTUDOS HANNAH ARENDT).

Arendt apresentou, em sua obra, questões que decorrem da existência real e concreta do Homo Totalitarius, fenômeno moderno que anteriormente era inexistente. A problemática após a publicação do seu livro gerou-se em torno da ambiguidade que a palavra "banalidade" transporta consigo naquele contexto concreto, pois a autora usou claramente o termo "banalização" de maneira intrínseca à sua forma relativista de pensar, tornando o seu livro ambíguo (CENTRO DE ESTUDOS HANNAH ARENDT).

Segundo Arendt, Eichmann era "uma pessoa completamente normal", que não tinha nenhum diagnóstico "psicopatológico". Ele era apenas o produto ou consequência do "consentimento" dado por homens e mulheres completamente "normais, tal Eichmann" (ARENDT, 1999, p. 33).

Neste contexto, o que merece destaque, para corroborar com o presente estudo é a Teoria da Banalização do Mal formulada pela autora, aliada à situação de pobreza e exclusão social que vivem milhares de pessoas hodiernamente. 
Quando Arendt discorreu sobre a Banalização do Mal, ela foi questionada que esta naturalização da indiferença não podia existir, que este olhar baço para o sofrimento dos outros só podia ser um ato de monstruosidade. Contudo, a autora mostra exatamente o contrário, ou seja, que é preciso rever o sentido da monstruosidade e do absurdo, já que o mal absoluto reside exatamente na banalização naturalizada (ARENDT, 1999).

Nesta perspectiva, a pobreza e a exclusão social se encaixa no termo banalização do mal, pois, muitas vezes, são entendidas como se fossem apenas um infortúnio ou um modo de estar exótico, primitivo e improvável, desconectado da expropriação sociocultural e econômica materializada nos corpos de quem vive a miséria todos os dias. Verifica-se que parece haver uma perversa perspectiva higienista, em que os pobres e suas histórias de vida são vistos como algo passível de ser apagado num processo banal de edição. Como se fosse possível, na experiência sinestésica e espetacular de "consumo", eliminar o outro, "tomar de assalto sua história e ocupar ficcionalmente o seu lugar", recriando, sobre a alteridade, a própria experiência banalizada (SANTOS, 2015, s.p.).

De um ou outro modo, nada é mais desanimador do que ver a banalização da pobreza, o esvaziamento vil do sofrimento humano, esta marcação do Outro como se fosse atração de um reality show ou testemunha distante da própria desaparição como sujeito que se insurge. Porque ao fim e ao cabo é isto que este povo espera: que os pobres encaixem numa narrativa ficcional para consumo ocasional e imediato ou que desapareçam de vez do campo de visão (SANTOS, 2015, s.p.).

Do mesmo modo, a exclusão social, também por vezes banalizada e naturalizada pelos próprios mecanismos que a produziram, resulta em sua aceitação nos níveis individuais e coletivos. Essa atmosfera social de conformismo seria reveladora da fragilização do vínculo social. Essas considerações podem ser caracterizadas como uma forma de violência simbólica, mais ou menos não percebida na vida cotidiana das populações menos favorecidas (Wanderley, 2001, p. 20-21).

Bourdieu afirma (1996, p. 268-269) que o mundo social não funciona em termos de consciência plena, mas em termos de práticas e de mecanismos, como a doxa e a ideologia, o que favorece muito mais a aceitação das coisas como elas são apresentadas, conhecendo-as apenas superficialmente sem haver, de fato, uma filosofia de mudança por parte dos indivíduos assim dominados ou, pelo menos, uma filosofia do questionamento crítico.

Nesse sentido, formas de apatia e de impotência predominam numa sociedade que incorpora a doxa e aceita sua própria exclusão por meio da internalização de crenças dominantes e opressoras. A heterodoxia, portanto, representaria um impulso emancipatório, 
um movimento de ruptura desse processo opressor de violência simbólica (BOURDIEU, 1996, p. 269-270).

Trazendo a problemática analisada para o cenário brasileiro, verifica-se que o país, ao longo de sua trajetória, tem convivido com acentuados contingentes de sua população na condição de pobreza. Observa-se que ao longo desse processo, tal questão apresenta características peculiares não no que se refere à sua redução em termos expressivos. O que se argumenta é quase sempre há uma tendência de ampliação, seja pelas suas formas de expressão ou pelo notório incremento de seu contingente em todos os momentos da nossa história (mais remota ou recente), a predominância de situações de empobrecimento, precariedade e de exclusão social, demonstrando também que existem crescentes níveis de desigualdade na distribuição do produto resultante da riqueza socialmente gerada (SILVA; BANDEIRA; LOPES, s.d., p. 4).

[...]podemos dizer que a pobreza associada à desigualdade social se configura no contexto brasileiro como um produto das relações sociais construídas as quais são permeadas por valores e princípios que produzem e reproduzem no plano econômico, político e nos aspectos culturais contradições e mecanismos que perpetuam e naturalizam os pobres nessa condição de verdadeira "apartação social", uma vez que estes são excluídos não só do acesso a patamares mínimos de renda para sua reprodução, mas também dos direitos legalmente constituídos que asseguram à condição de cidadania (SILVA; BANDEIRA; LOPES, s.d., p.4-5).

Atualmente, conforme a avaliação divulgada em fevereiro de 2017 pelo Banco Mundial, o Brasil deverá presenciar um aumento ainda maior de pessoas vivendo na pobreza até o final do corrente ano. Esses resultados se deram por causa da prolongada crise econômica que enfrenta o país nos últimos anos. Constatou-se que "o Brasil deverá testemunhar um aumento de 2,5 milhões até 3,6 milhões no número de pessoas vivendo na miséria", resultado da prolongada crise econômica (BANCO MUNDIAL, 2017).

O organismo financeiro traçou um perfil desses "novos pobres", utilizando, como parâmetros, brasileiros homens com menos de 40 anos, moradores de zonas urbanas, que concluíram pelo menos o Ensino Médio e estavam empregados em 2015, sobretudo no setor de serviços. O Banco Mundial também recomendou, para diminuir os impactos da crise sobre a população, a expansão do Programa Bolsa Família ${ }^{6}$, que deverá ter seu orçamento ampliado

\footnotetext{
${ }^{6}$ O Bolsa Família é um programa de transferência de renda do Governo Federal para auxiliar as famílias em situação de pobreza e de extrema pobreza. De acordo com o Ministério do Desenvolvimento Social e Combate à Fome (MDS), o benefício atende mais de 13 milhões de famílias em todo o Brasil. Essa ajuda de custo contribui bastante para pessoas que não tem emprego fixo ou não o conseguem, mas precisam sustentar filhos, netos, etc. (BRASIL).
} 
para 30,7 bilhões de reais durante o ano de 2017, com o objetivo de reduzir os impactos sobre os "novos pobres" por meio da proteção social. Através desse aumento, seria possível um acréscimo de cerca de 900 milhões de reais na verba prevista para o programa pela lei orçamentária de 2017 (BANCO MUNDIAL, 2017).

O aumento na pobreza para este ano foi calculado com base em variações distintas de índices macroeconômicos. No cenário mais otimista, o Banco Mundial estima uma retomada do crescimento econômico, com um modesto saldo positivo - de 0,5\% - para o Produto Interno Bruto (PIB). O desemprego continuaria em ascensão, chegando aos $11,8 \%$, valor $0,6 \%$ mais alto do que a taxa de desocupação no ano passado.

Na previsão mais pessimista, o Brasil continuará em recessão, com o PIB registrando contração de $1 \%$. O desemprego alcançaria os $13,3 \%$.

Nas melhores circunstâncias, o número de pessoas moderadamente pobres atingirá os 19,8 milhões ( $9,8 \%$ da população), incluindo os que viverão na miséria extrema - cerca de 8,5 milhões de indivíduos $(4,2 \%)$ em 2017. A linha de pobreza utilizada para os cálculos foi estipulada como 140 reais per capita por mês.

No pior cenário, a pobreza chega a 10,3\% - 20,8 milhões de brasileiros - e a pobreza extrema alcançará os 4,6\% - 9,3 milhões. Em 2016, a miséria extrema havia sido calculada em $3,4 \%$.

Caso os investimentos no Bolsa Família sejam realizados, a proteção social poderia frear o crescimento da miséria extrema, que alcançaria $3,5 \%$ e $3,6 \%$ nas simulações mais otimista e mais pessimista, respectivamente. Os valores ficariam bem próximos aos verificados em 2015 (BANCO MUNDIAL, 2017).

O Banco Mundial (2017) afirma que foram os programas de transferência de renda que reduziram o nível de miséria no Brasil. Ou seja, cinquenta e oito por cento da queda na pobreza extrema no país registrada entre 2004 e 2014 está associada a mudanças nos rendimentos de fontes que não incluíam o trabalho, e sim, projetos sócio-Estatais como o Bolsa Família.

Através da avaliação traçada pelo órgão financeiro com chefes de famílias, foi verificado que esses brasileiros não eram miseráveis em 2015. “Eles têm nível de qualificação - 38,2\% concluíram pelo menos o Ensino Médio - muito próximo ao da camada de não pobres, dos quais $41,3 \%$ têm, no mínimo, escolaridade média." Portanto, os "novos pobres" tinham trabalho dois anos atrás, mas entraram para as estatísticas dos desempregados (BANCO MUNDIAL, 2017, s.p.).

Além disso, o nível da formação revelado pelo Banco Mundial (2017) distancia os dois segmentos mencionados dos considerados estruturalmente pobres brasileiros, que já eram pobres em 2015 e continuarão vivendo na miséria. Entre esses, apenas 17,5\% terminou o Ensino Médio e 63,7\% vivem em áreas rurais. Quase 90\% dos "novos pobres" vivem em zonas urbanas. 
Destaca-se que, de todas as pessoas que chegarão à linha da pobreza em 2017, 33,5\% são brancos, em comparação aos $24,2 \%$ dos brancos descritos como vítimas estruturais da desigualdade. Também, outra informação calculada pelo organismo financeiro é a faixa etária dos chefes das famílias dos "novos pobres". Eles têm em média 37,9 anos, enquanto, entre os estruturalmente pobres, a média sobe para 41 anos. No grupo de não pobres, a idade chega a 50,4 (BANCO MUNDIAL, 2017).

Por fim, a orientação do organismo financeiro foi que a duração da atual crise econômica no Brasil pode ser vista como uma oportunidade para que o governo amplie o papel do Bolsa Família "que passaria de um eficaz programa de redistribuição de renda para uma verdadeira rede de proteção, flexível o suficiente para expandir a cobertura aos domicílios dos "novos pobres" (BANCO MUNDIAL, 2017, s.p.).

Contudo, ainda que o Programa Bolsa Família seja visto como uma possível restauração na perspectiva de assegurar uma renda mínima às famílias pobres para que estas atendam às suas necessidades imediatas, parece que tais ações ainda estão muito distantes de serem vistas como capazes de combater a pobreza. Por isso, só será possível enfrentar a pobreza se houver medidas direcionadas para mudanças estruturais concretas e sustentáveis num longo prazo. Uma das possibilidades de mudanças seria o desenvolvimento econômico, também a ampliação de políticas sociais públicas, a criação de oportunidades de trabalho e de renda para os milhões de trabalhadores brasileiros.

Ante a impossibilidade de completude de apreciação do impacto da pobreza no Brasil, assim como, da banalização e exclusão social do pobre, mas já considerando como situada essa questão, passa-se a análise do seguinte tópico: a pobreza como supressão das capacidades, tendo como baluarte as concepções de Amartya Sen.

\section{A POBREZA COMO SUPRESSÃO DAS CAPACIDADES A PARTIR DAS CONCEPÇÕES DE AMARTYA SEM}

Na contemporaneidade, muito se discute sobre a erradicação da pobreza, bem como sobre todos os demais impasses que ela proporciona na sociedade. Porém, na grande maioria das análises e pesquisas feitas, poucos foram os estudiosos que adentraram e esmiuçaram questões mais especificas da pobreza e o efeito que ela causa nos indivíduos. No entanto, o economista indiano Amartya Sen destaca muitos argumentos em favor da abordagem da pobreza como privação de capacidades. 
De acordo com as concepções de Amartya Sen, "a pobreza é conceituada como uma privação de capacidades básicas e não apenas como a expressão de baixa renda" (SEN, 2000, p.109). Explicitamente, essa privação dificulta a realização de renda e igualmente dificulta a conversão dos valores em funcionamento socialmente adequados. Logo, segundo a perspectiva das capacidades humanas, existe uma relatividade da riqueza em relação à pobreza. A título de exemplo, alguém que é rico, mas que padece de enfermidade grave e intratável tem uma privação que, em sentido significativo, pode ser maior que a de um trabalhador pobre desempregado, mas sadio, que conta com auxílio do seguro-desemprego (SEN, 2000, p.109110).

Ao mencionar "capacidade", Sen compreende ser as combinações alternativas de funcionamentos de possível realização. Portanto, a capacidade é um tipo de liberdade: a liberdade substantiva de realizar combinações alternativas de funcionamentos ou a liberdade para ter estilos de vida diversos. Por exemplo, uma pessoa abastada que faz jejum por sua livre e espontânea vontade pode ter a mesma realização de funcionamento que uma pessoa pobre forçada a passar fome extrema. Porém a primeira pessoa possui um "conjunto capacitário" diferente da segunda. A primeira pode escolher comer bem e ser bem nutrida de um modo impossível para a segunda (SEN, 2000).

A questão central é a qualidade de vida que podemos levar. A necessidade de possuir mercadorias para que se alcance um determinado patamar de condições de vida varia grandemente segundo características fisiológicas, sociais e culturais, além de outras igualmente contingentes [...] O valor do padrão de vida repousa na vida, e não na possessão de mercadorias, a qual tem relevância derivada e variável (SEN, 1990, p.25).

Sen afirma que os funcionamentos são definidos como o que uma pessoa pode considerar valioso fazer ou ter. Logo, podem ter variantes elementares, como ser adequadamente nutrido e livre de doenças evitáveis, a atividades ou estados pessoais muito complexos, poder participar da vida da comunidade e ter respeito próprio. Por isso, a privação de capacidades elementares pode refletir-se em morte prematura, subnutrição considerável (especialmente de crianças), morbidez persistente, analfabetismo e outras deficiências. Essa definição não despreza o fato de a pobreza também ser caracterizada como uma renda inferior a um patamar pré-estabelecido, pois uma renda baixa pode ser a razão primeira da privação de capacidades de uma pessoa (SEN, 2000).

Tal como o assim chamado "conjunto orçamentário" no espaço de mercadorias representa a liberdade de uma pessoa para comprar pacotes de mercadorias, o "conjunto capacitário" [capability set] reflete, no 
espaço de funcionamentos, a liberdade da pessoa para escolher dentre vidas possíveis (Sen, 2000, p.80).

en também explica que a relação entre renda e capacidade é demasiadamente afetada pela idade da pessoa (necessidades específicas dos idosos e muito jovens), pelos papéis sexuais e sociais (por exemplo, as responsabilidades da maternidade e também as obrigações familiares determinadas culturalmente), pela localização (por exemplo, propensão a inundações ou secas, ou insegurança e violência em alguns bairros pobres e muito populosos), pelas condições epidemiológicas (por exemplo, doenças endêmicas em uma região) e por outras variações sobre as quais uma pessoa pode não ter controle ou ter um controle apenas limitado (SEN, 2000, p.110-112).

Desvantagens, como idade, incapacidade ou doença, reduzem o potencial do indivíduo para auferir renda. Além disso, também tornam mais difícil converter renda em capacidade, já que uma pessoa mais velha, mais incapacitada ou mais gravemente enferma podem necessitar de mais renda (para assistência, próteses, tratamentos) para obter os mesmos funcionamentos. Isso implica que a pobreza real (no que se refere à privação de capacidades) pode ser mais intensa do que possa parecer no espaço da renda.

Existem circunstâncias individuais (tais como idade, talentos e deficiências, propensão à doença, sexo) e sociais (tais como a estrutura da família, disponibilidade de uma rede de segurança previdenciária, condições epidemiológicas, extensão da poluição, incidência de crimes) cujas variações afetam substancialmente a conversão de características de bens e serviços em atividades e estados pessoais e em oportunidades que uma pessoa dispõe para realizar coisas que considera valiosas". (Sen, 2000, p.15).

Logo, a distribuição de renda dentro da família acarreta complicações adicionais na abordagem da pobreza baseada na renda. Se a renda familiar é usada desproporcionalmente no interesse de alguns membros da família em detrimento de outros (por exemplo, se existe uma preferência generalizada pelos meninos na alocação dos recursos da família), o grau de privação dos membros negligenciados (no exemplo em questão, as meninas) pode não ser evidenciado pela renda familiar. Com isso, a privação das meninas é mais facilmente constatada quando se verifica a privação de capacidades (mortalidade, morbidez, subnutrição, negligência médica, mais elevadas) em oposição ao uso da análise baseada na renda (SEN, 2000, p. 110).

O que a perspectiva da capacidade faz na análise da pobreza é melhorar o entendimento da natureza e das causas da pobreza e privação, desviando a atenção principal dos meios (renda) para os fins que as pessoas têm razão para buscar e para as liberdades de poder alcançar esses fins (SEN, 2000, p. 115). 
Por isso, ambas as perspectivas, a noção de pobreza como inadequação de capacidade e a noção de pobreza como baixo nível de renda, estão vinculadas, uma vez que a renda é um meio fundamental na obtenção de capacidade. Quanto mais capacidades, maior o potencial produtivo de uma pessoa e, consequentemente, maior a chance de se obter uma renda mais elevada (SEN, 2000, p. 118-119).

Uma renda mais elevada não significa necessariamente capacidades maiores. Essa relação, portanto, é importante na eliminação da pobreza de renda. Com uma educação básica e serviços de saúde melhores há um aumento no potencial do indivíduo de auferir renda e de, assim, livrar-se da pobreza medida pela renda. Quanto mais inclusivo for o alcance da educação básica e dos serviços de saúde, maior será a probabilidade de que mesmo os potencialmente pobres tenham uma chance maior de superar a penúria (SEN, 2000, p.118).

Segundo Sen, é importante ter em mente que a redução da pobreza de renda não pode ser o único objetivo de políticas de combate à pobreza. É perigoso ver a pobreza segundo a perspectiva limitada da privação de renda e a partir disso justificar investimentos em educação, serviços de saúde, etc., com o argumento de que são bons meios para a redução da pobreza. Isso seria confundir os fins com os meios. A pobreza deve ser entendida como a privação da vida que as pessoas realmente podem levar e das liberdades que elas realmente têm (SEN. 2000, p. 119).

A expansão das capacidades humanas enquadra-se justamente nesse ponto. Não se pode esquecer que o aumento das capacidades humanas tende a caminhar junto com a expansão das produtividades e do poder de auferir renda. Um aumento de capacidades ajuda direta e indiretamente a enriquecer a vida humana e a tornar as privações humanas mais raras e menos crônicas. As relações instrumentais, por mais importantes que sejam, não podem substituir a necessidade de uma compreensão básica da natureza e das características da pobreza.

Em sua obra "Desenvolvimento como Liberdade", Sen (2000) identifica os apontamentos referidos acima como cinco fontes de variação na conversão de renda em bemestar e liberdade. Seriam elas: a) heterogeneidades pessoais; b) diversidades ambientais; c) variações no clima social; d) diferenças de perspectivas relativas; e) distribuição na família.

Por isso, a existência de tamanhas variações sociais e interpessoais parece deixar uma interrogação sobre o que realmente importa para o bem-estar de uma pessoa. Sen (2001) intercede no sentido de que tais variações não eliminam os diversos consensos sobre o que irá contar como privação grave. Por exemplo, é provável que haja mais acordo sobre a importância 
de evitar a fome aguda ou a subnutrição do que um acordo sobre os itens que devem constar na alimentação de um indivíduo.

A análise das diferentes fontes de variação na relação entre renda e bem-estar demonstra que renda elevada, por si só, não garante bem-estar ou liberdade individual. Esta seria, conforme Sen, uma grande fragilidade da métrica da renda:

"[...] o efeito de ignorar-se as variações interpessoais pode ser, na verdade, profundamente não igualitário, ao esconder o fato de que a igual consideração de todos pode demandar um tratamento bastante desigual em favor dos que estão em desvantagem." (Sen, 2000, pp.29-30)

Assim, rendas iguais podem deixar bastante desiguais os níveis de qualidade de vida de duas pessoas distintas. As características individuais e sociais diferem substancialmente, o que resulta em variações interpessoais expressivas na conversão de recursos em realizações ou bem-estar. A abordagem dos funcionamentos e capacitações tem o mérito de levar em conta estas variações, por esta razão, comparações interpessoais de bem-estar são feitas mais proficuamente com base nesta perspectiva.

Inúmeras são as causas que levam um país ou comunidade à pobreza, à miséria, a praticar delitos, entre outras circunstâncias. Dessa maneira, levando em consideração as contribuições de Amartya Sen, a redução efetiva da pobreza e da privação de capacidades advém de variados fatores que devem ser analisados, devendo ser passíveis de discussão como possíveis mecanismos de políticas públicas governamentais (SEN, 2000, p.114).

Nessa perspectiva, investimentos na educação, saúde e projetos habitacionais também são salutares para que se possa alavancar a economia de um país, comunidades e seus cidadãos, e também grande imissão para as futuras gerações e suas necessidades básicas (SEN, 2000, p. 35). Um dos grandes problemas dos países e comunidades que sofrem com a pobreza, marginalização e incapacidades é a falta de investimentos do Estado em direitos básicos da população, dessa forma, as desigualdades agravam as privações de capacidades, acarretando menores possibilidades de emprego, liberdade e qualidade de vida.

Ademais, "há provas abundantes de que o desemprego tem efeitos além da perda de renda, como dano psicológico, perda de motivação para o trabalho, perda de habilidade e autoconfiança" (SEN, 2000, p. 117). A pobreza e privação de capacidades não podem ser focadas somente em detrimento da renda, visto que doenças, perturbação nas relações familiares, exclusões sociais, racismo e discriminações sexuais também as causam.

Nessa perspectiva, na atualidade são muitas as inversões de valores no Estado Democrático de Direito diante de tantas desigualdades e, para que este fosse efetivado de uma 
forma ideal proporcionando a possibilidade de desenvolvimento de todos os cidadãos pode se afirmar que:

A efetivação do ideal democrático precisa ser permeada por inúmeras ações que contribuam eficazmente para o aprimoramento da atuação do Estado, dos mecanismos de participação e do atendimento das necessidades dos seus habitantes, entre outras. As diferentes áreas do desenvolvimento (econômico, social, humano e outras) não possuem legitimidade moral quando estruturadas pelos interesses dos governos autoritários, de Estados repressivos ou de instituições que sustentam seus interesses (ZAMBAM, 2012, p. 206).

Entretanto, em um Estado Democrático, devem ser respeitados os direitos fundamentais das pessoas, pois estão vinculadas a todos os modelos de classes sociais, ciclos econômicos, culturais e políticos que o meio social faz parte, os quais garantem a aplicabilidade em conformidade com as bases jurídicas, uma série de direitos e garantias basilares dos seres humanos. Dentre eles, o direito à vida, à saúde, à integridade física, à igualdade (no sentido formal e material), dentre outros elementos que objetivam a proteção do ser humano e, igualmente, a potencialização do seu desenvolvimento com dignidade.

Ademais, conforme o estudo de Amartya Sen, a mudança deve começar pelas necessidades básicas da população, em especial a saúde, educação e projetos habitacionais, pois a pobreza é um fenômeno multidimensional em que há a falta do que é necessário para o bem-estar material. Assim, associa-se a esse conceito a falta de voz, poder e independência dos pobres que os sujeita à exploração; à propensão à doença; à falta de infraestrutura básica, à falta de ativos físicos, humanos, sociais e ambientais e à maior vulnerabilidade e exposição ao risco

\section{CONCLUSÃO}

A banalização da pobreza pode partir de múltiplas perspectivas. Observa-se que os modelos que se orientam pelo critério exclusivo da insuficiência de renda, normalmente utilizada, constituem apenas um dos dados avaliatórios dentre tantos outros para a identificação das necessidades individuais. Amartya Sen, um dos estudiosos do tema, sugere a não-existência de equivalência plena entre aumento da renda e melhoria da qualidade de vida, visto que a renda, por si só, não se converte necessariamente em várias realizações importantes para o bem-estar humano.

Por isso, Sen (2000) entende que a pobreza deve ser entendida como uma composição de privações econômicas e não-econômicas, posto que as pessoas não encontram valor apenas 
na posse de bens e acesso aos serviços, mas essencialmente naquilo que podem ser e fazer com base na liberdade de que desfrutam. Logo, a posição de um indivíduo em um ordenamento social deve ser também apreciada em função dos estados e ações que ele realiza ao viver, os chamados funcionamentos, e da forma como estes estados e ações venham a emergir, ou seja, se foram fruto de uma efetiva liberdade de escolha da pessoa ou não.

Durante a organização desse estudo, foi feita uma introdução acerca das principais abordagens sobre a banalização da pobreza no Brasil e sobre o seu desenvolvimento na atualidade, a partir da Avaliação do Fundo de Combate e Erradicação da Pobreza realizada no país em 2017 pelo Banco Mundial, bem como tendo como base as percepções de pobreza como privação de capacidades desenvolvidas por Amartya Sen.

Na primeira parte do artigo foram descritas as abordagens do fenômeno da pobreza e o seu desenvolvimento ao longo do último século. Assim, inicialmente, tratou-se das categorias nas quais se enquadram os conceitos de pobreza: pobreza como juízo de valor, pobreza relativa, pobreza absoluta e pobreza relativa/absoluta, particularizando em um item dentro do referido capítulo o impacto da pobreza no Brasil, discorrendo sobre a banalização e exclusão social do pobre no contexto atual. Para tanto, partiu-se da Teoria da Banalidade do Mal de Hannah Arendt e, ainda, trazendo os dados apurados pelo Banco Mundial na Avaliação do Fundo de Combate e Erradicação da Pobreza realizada no país em 2017.

Por conseguinte, no segundo ponto foram examinadas as contribuições de Amartya Sen sobre as privações das capacidades dos indivíduos e como isso se relaciona com a pobreza na atualidade. A análise efetuada partiu do conceito de pobreza estabelecido pelo referido autor e de outras fontes de conhecimento trabalhadas pelo mesmo.

Conclui-se, com base no estudo realizado, que a banalização da pobreza no Brasil, assim como em muitos outros lugares do planeta, está além da renda ou valores monetários percebidos por um determinado indivíduo. Conforme Amartya Sen, (2000) a relação entre os recursos e a pobreza é variável e profundamente dependente das características das respectivas pessoas e do ambiente em que vivem, tanto natural como social. Por isso, a problemática se firma quando resulta na relevância das inaptidões e na compreensão dessas privações que, na maior parte, é subestimada pelo mundo, e esse pode ser um dos argumentos mais importantes para prestar atenção na perspectiva da capacidade.

Quando se discute em relação a banalidade da pobreza, se abre um leque de situações que se naturalizam no cotidiano e muitas vezes passam desapercebidas pela sociedade, como 
se fizessem parte daquele contexto sem causar quaisquer sentimentos de repulsa aos demais sujeitos.

Em vista disso, a banalização da pobreza no Brasil advém de um longo processo histórico, principalmente, de um quadro de extrema desigualdade, que desenvolveu um sistema socioeconômico tipicamente excludente e concentrador e seu agravamento se deu na mesma proporção ou acompanhado do desenvolvimento do sistema capitalista, aliado aos processos de industrialização e de urbanização das cidades.

Dessa forma, embora a trajetória da pobreza apresente características peculiares, conforme as perspectivas de Amartya Sen, é notório que em todos eles há a predominância de situações de empobrecimento, precariedade e de exclusão social de vastos contingentes populacionais, o que mostra que a sociedade parece ter erguido uma parede que se torna fixa separando ricos e pobres, abastados e destituídos e o que é pior, sob a aparência de normalidade, ou melhor dizendo, banalização.

\section{REFERÊNCIAS}

SILVA, Abinoã Cunha; BANDEIRA, Ellen Suenne F.; LOPES, Ester Borges. Pobreza No Brasil: aspectos conceituais e o processo de construção histórica. V Jornada Internacional de Políticas Públicas.

<http://www.joinpp.ufma.br/jornadas/joinpp2011/CdVjornada/jornada_eixo_2011/desigualdad es_sociais_e_pobreza/no_brasil_aspectos_conceituais_e_o_processo_de_construcao_historica .pdf> Acesso em 12 de dez. de 2017.

ARENDT, Hannah. Eichmann em Jerusalém: Um relato sobre a banalidade do mal. Hannah Hannah Arendt; trad. José Rubens Siqueira. - São Paulo: Companhia das Letras, 1999.

BOURDIEU, P.; EAGLETON, T. A doxa e a vida cotidiana: uma entrevista. In: ZIZEK, Slavoj. (Org.). Um mapa de ideologia. Rio de Janeiro: Contraponto, 1996, p. 265-278.

BANCO MUNDIAL, Word Bank Group. Salvaguardas Contra a Reversão dos Ganhos Sociais Durante a Crise Economica no Brasil. Disponivel em:

< https://nacoesunidas.org/wp-content/uploads/2017/02/NovosPobresBrasil_Portuguese.pdf> Acesso em 12 de 
dez. de 2017.

CRESPO, Antônio Pedro A.; GUROVITZ, Elaine. A pobreza como um fenômeno multidimensional. Revista ERA Eletrônica, São Paulo, v.1, n. 2, p.1-12, jul./dez 2002.

HANNAH ARENDT STUDIES CENTER. Centro de Estudos Hannah Arendt. Disponível em: < http://www.hannaharendt.org.br/hannah-arendt> Acesso em 12 de dez. de 2017.

HR IDIOMAS, The Academy of Languages. Origem da palavra Pobreza. Disponível em:< http://hridiomas.com.br/origem-da-palavra-pobreza/> Acesso em 10 de dez. de 2017.

MEDEIROS, Marcelo. Medidas de Desigualdade e Pobreza. Brasília: Editora UnB, 2012.

PNUD, Brasil. Relatório de Desenvolvimento Humano 2013. Disponível em:

< http://hdr.undp.org/sites/default/files/hdr2013_portuguese.pdf> Acesso em 10 de dez. de 2017.

SANTOS, Luciana Lucca. Consumo cultural, banalização da pobreza e o outro como ficção de si. Disponível em:< http://monoculturadoconsumo /2015/07/a-vida-quotidiana-e-banalizacaodo.html> Acesso em 12 de dez. de 2017.

SOARES, Sergei. Metodologias para estabelecer a linha de pobreza: objetivas, subjetivas, relativas, multidimensionais. IPEA: Texto para Discussão nำ1381. Rio de Janeiro: 2009. Disponível em: $<$ http://www.ipea.gov.br/portal/index.php?option=com_content\&view=article\&id=4933> Acesso em 10 de dez. de 2017.

SEN, Amartya. The Standard of living. Cambridge: Cambridge University Press, 1990.

Desenvolvimento como liberdade. Laura Teixeira Motta. São Paulo: Companhia de letras, 2000. 
OIC, Observatório Internacional de Capacidades Humanas, Desenvolvimento e Políticas Públicas. Sobre Amartya Sen. Disponivel em: < http://capacidadeshumanas.org/sobre-amartyasen/>Acesso em 10 de dez. de 2017.

ONU, Organização das Nações Unidas. Erradicação da Pobreza: acabar com a pobreza em todas suas formas, em todos os lugares. Documentos Temáticos Naçoes Unidas do Brasil. Disponível em:< https://nacoesunidas.org/wp-content/uploads/2017/06/Documento-Tem\%C3\%A1ticoODS-1-Erradica\%C3\%A7\%C3\%A3o-da-Pobreza_11junho2017.pdf> Acesso em: 15 de dez. de 2017.

ONU. Relatório do desenvolvimento humano 2016: human development for everyone. New York: UNDP, 2016.

OSORIO, R.; SOARES, S.; SOUZA, P. Erradicar a pobreza extrema: um objetivo ao alcance do Brasil. Texto para Discussão no1619. Brasília, 2011. Disponível em:< http://www.ipea.gov.br/portal/images/stories/PDFs/TDs/td_1619.pdf> Acesso em: 10 de maio de 2017.

WANDERLEY, M. B. Refletindo sobre a noção de exclusão. In: SAWAIA, B. (Org.). As artimanhas da exclusão: análise psicossocial e ética da desigualdade social. Petrópolis: Vozes, 2001.

ZAMBAM, Neuro José. Amartya Sen: liberdade, justiça e desenvolvimento sustentável. Passo Fundo, IMED, 2012.

Trabalho enviado em 06 de julho de 2018

Aceito em 25 de agosto de 2018 